\title{
Distal Radioulnar Joint
}

National Cancer Institute

\section{Source}

National Cancer Institute. Distal Radioulnar Joint. NCI Thesaurus. Code C139194.

The articulation of the head of the ulna bone and the ulnar notch of the radius; the distal radioulnar joint is a pivot joint that functions in pronation and supination of the forearm. 